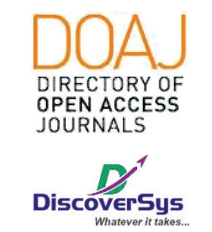

Published by DiscoverSys

\title{
Gambaran prevalensi penderita sifilis laten, sekunder, dan primer pada pasien Infeksi Menular Seksual (IMS) di Poliklinik Kulit dan Kelamin RSUD Mangusada, Badung, Bali periode 2017 - 2018
}

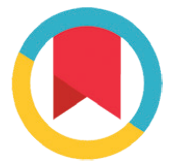

CrossMark

\author{
Komang Indah Permata Dewi, ${ }^{*}{ }^{*}$ Anak Agung Ari Agung Kayika Silayukti ${ }^{2}$
}

\section{ABSTRACT}

Background: Venereal disease (syphilis) has long been known in Indonesia. However, the clinical manifestations of syphilis differ according to the stage in which they affect the treatment plan. Therefore, this study aims to determine the prevalence of latent, secondary and primary syphilis in sexually transmitted infections (STI) patients in the Skin and Venereal Polyclinic of Mangusada Regional Hospital, Badung.

Methods: A cross-sectional observational study was conducted on secondary data from the medical records of Syphilis patients at the Mangusada Badung Hospital \& Gynecology Clinic in January 2017-December 2018 using a total sampling technique. Syphilis prevalence in patients mainly from gender and clinical manifestations of syphilis are noted in this study. The data obtained were analyzed descriptively with SPSS software version 20 for Windows.

Results: Total visits of cases of sexually transmitted infections (STI) were recorded as many as 332 people where syphilis cases were obtained by 35 cases (10.54\%) with the proportion of new cases in syphilis patients by 28 cases $(80.0 \%)$. Advanced stage syphilis was acquired in 32 cases (91.42\%) followed by secondary stage (S-II) in 3 cases (8.58\%) and there were no cases of manifestation of primary stage syphilis (0.00\%). Based on sex, syphilis sufferers are dominated by women with 22 people (62.85\%\%) while male gender is 13 people (37.15\%).

Conclusion: Most of the new syphilis cases in Mangusada Regional Hospital, Badung were found at patient visits with STls, had advanced stage manifestations, and were dominated by female sex.

Keywords: STD, Syphilis, Prevalence, STI, Clinical Stadium

Cite This Article: Dewi, K.I.P., Silayukti, A.A.A.A.K. 2020. Gambaran prevalensi penderita sifilis laten, sekunder, dan primer pada pasien Infeksi Menular Seksual (IMS) di Poliklinik Kulit dan Kelamin RSUD Mangusada, Badung, Bali periode 2017 - 2018. Intisari Sains Medis 11(2): 457-460. DOl: $10.15562 /$ ism.v11i2.586

Latar Belakang: Penyakit kelamin (veneral disease) seperti sifilis sudah lama di kenal di Indonesia. Akan tetapi, manifestasi klinik penyakit sifilis berbeda sesuai dengan tahapannya dimana berdampak pada rencana pengobatan. Oleh karena itu penelitian ini bertujuan untuk mencari tahu gambaran prevalensi sifilis laten, sekunder, dan primer pada pasien Infeksi Menular Seksual (IMS) di Poliklinik Kulit dan Kelamin RSUD Mangusada, Badung.

Metode: Penelitian observasional potong lintang dilakukan terhadap data sekunder dari rekam medis pasien Sifilis di Poliklinik Kulit \& Kelamin RSD Mangusada Badung pada Januari 2017-Desember 2018 dengan menggunakan teknik total sampling. Prevalensi Siflis pada pasien terutama dari jenis kelamin dan manifestasi klinis sifilis dicatat pada peneltian ini. Data yang diperoleh dianalisis secara deskriptif dengan piranti lunak SPSS versi 20 untuk Windows.
Hasil: Total kunjungan kasus infeksi menular seksual (IMS) tercatat sebanyak 332 orang dimana kasus sifilis diperoleh sebesar 35 kasus $(10,54 \%)$ dengan proporsi kasus baru pada penderita sifilis sebesar 28 kasus $(80,0 \%)$. Sifilis stadium lanjut diperoleh sebanyak 32 kasus $(91,42 \%)$ diikuti dengan stadium sekunder (SII) sebanyak 3 kasus $(8,58 \%)$ dan tidak terdapat kasus manifestasi sifilis stadium primer $(0,00 \%)$. Berdasarkan jenis kelamin, penderita sifilis didominasi oleh perempuan dengan jumlah 22 orang $(62,85 \% \%)$ sedangkan jenis kelamin pria berjumlah 13 orang $(37,15 \%)$.

Kesimpulan: Sebagian besar kasus baru sifilis di RSUD Mangusada, Badung ditemukan pada kunjungan pasien dengan IMS, memiliki manifestasi stadium lanjut, dan didominasi oleh jenis kelamin perempuan.
Komang Indah Permata Dewi, Dokter Umum, Poliklinik Kulit dan Kelamin, RSUD Mangusada Badung, Bali, Indonesia

indahpermatadw@yahoo.co.id

Diterima: $15-08-2019$

Disetujui: $10-07-2020$

Diterbitkan: 01-08-2020

\section{Kata Kunci: STD, Sifilis, Prevalensi, IMS, Stadium Klinis}

Cite Pasal Ini: Dewi, K.I.P., Silayukti, A.A.A.A.K. 2020. Gambaran prevalensi penderita sifilis laten, sekunder, dan primer pada pasien Infeksi Menular Seksual (IMS) di Poliklinik Kulit dan Kelamin RSUD Mangusada, Badung, Bali periode 2017 - 2018. Intisari Sains Medis 11(2): $457-460$. DOl: 10.15562/ism.v11i2.586 


\section{LATAR BELAKANG}

Penyakit kelamin (veneral disease) sudah lama di kenal di Indonesia. ${ }^{1}$ Semakin berkembang dan majunya ilmu pengetahuan maka banyak penyakit-penyakit baru yang mulai ditemukan, sehingga istilah penyakit kelamin tidak sesuai lagi yang kemudian diubah menjadi Sexually Transmitted Diseases (STD) atau Penyakit Menular Seksual (PMS). ${ }^{2}$ Kemudian sejak 1998, istilah Sexually Transmitted Diseases (STD) berubah menjadi Infeksi menular seksual (IMS) agar dapat menjangkau penderitaan asimptomatik..$^{1,2}$

Penyakit Infeksi Menular Seksual (IMS) masih tetap merupakan masalah kesehatan masyarakat baik ditinjau dari segi kesehatan, politik, maupun sosial ekonomi. ${ }^{3}$ Kegagalan dalam diagnosis, maupun terapi pada tahap dini, mengakibatkan timbulnya komplikasi yang cukup serius, misalnya infertilitas, kehamilan ektopik, kematian janin, infeksi neonates, bayi dan berat badan lahir rendah, kanker anogenital, bahkan dapat menyebabkan kematian. ${ }^{4,5}$ Data Infeksi menular seksual (IMS) merupakan salah satu dari sepuluh penyebab pertama penyakit yang tidak menyenangkan pada dewasa muda laki-Iaki dan penyebab kedua terbesar pada dewasa muda perempuan negara berkembang. ${ }^{6}$ Dewasa dan remaja (15-24 tahun) merupakan $25 \%$ dari semua populasi yang aktif secara seksual, tetapi memberikan konstribusi hampir 50\% kasus IMS baru yang ditemukan. ${ }^{7}$

Sifilis merupakan salah satu dari penyakit Infeksi Menular Seksual (IMS) yang sangat popular di Indonesia. ${ }^{8}$ Sifilis ini disebabkan oleh bakteri Treponema pallidum. ${ }^{9}$ Kemampuam penyakit sifilis untuk menyerupai banyak penyakit menyebabkan penyakit ini dikenal sebagai "The Great Imitator". Sifat penyakit sifilis yaitu, kronik dan sistemik, dapat menyerang hampir semua organ tubuh hingga dapat ditularkan melalui ibu ke janin. ${ }^{9}$ Dampak dari sifilis ini sangat besar bagi kesehatan seksual, kesehatan reproduksi, dan kehidupan sosial. Populasi berisiko tertular sifilis meningkat dengan adanya perkembangan dibidang sosial, demografik, serta meningkatnya migrasi penduduk. ${ }^{10}$

Negara berkembang memiliki angka kejadian sifilis yang hampir mencapai $90 \%$ di seluruh dunia. ${ }^{10}$ Badan Kesehatan Dunia atau World Health Organization (WHO) memperkirakan 5 juta kasus baru sifilis di dunia dan 12 juta kasus baru terjadi dibeberapa negara yaitu, Afrika, Asia Selatan, Asia Tenggara, Amerika Latin dan Caribbean..$^{10}$ Pada wilayah Asia Tenggara didapatkan 3 juta kasus baru pada tahun 2008. ${ }^{11}$ Angka kejadian sifilis di Indonesia berdasarkan laporan Survey Terpadu Dan Biologis Perilaku (STBP) tahun 2011 oleh Kementrian Kesehatan RI, terjadi peningkatan angka kejadian sifilis di tahun 2011 jika dibandingkan dengan tahun 2007. ${ }^{11}$ Sedangkan di Indonesia sendiri angka insidensinya sekitar $0,61 \% .^{11}$

Pengkajian mengenai prevalensi sifilis merupakan suatu langkah yang dapat dilakukan untuk melihat perkembangan kasus sifilis, penyakit ini memiliki kemampuan yang mudah menyerupai berbagai macam penyakit hingga memiliki kemungkinan tidak diketahui dengan baik. Hal ini erat kaitannya dengan rumah sakit yang menjadi salah satu lini utama penyedia pelayanan kesehatan tingkat rujukan dan spesialis. Berkaitan dengan pemaparan di atas, maka penelitian ini bertujuan untuk menentukan gambaran penyakit berdasarkan faktor terkait dimana informasi dasar yang diperoleh dapat dipergunakan oleh para pemangku kebijakan, tenaga kesehatan, maupun peneliti untuk dapat memberikan pelayanan yang komprehensif dalam menurunkan angka morbiditas, komorbiditas, disabilitas, dan mortalitas akibat penyakit ifilis.

\section{METODE PENELITIAN}

Penelitian ini menggunakan pendekatan observasional dengan teknik potong lintang (crosssectional) yang dilakukan terhadap data sekunder dari rekam medis pasien Sifilis di Poliklinik Kulit \& Kelamin RSD Mangusada Badung pada periode Januari 2017-Desember 2018. Adapun teknik pengambilan sampel penelitian terhadap rekam medis yang dipergunakan adalah menggunakan teknik total sampling.

Beberapa parameter yang diteliti pada penelitian pendahuluan deskriptif ini adalah jenis kelamin dan manifestasi klinis sifilis yang di dapatkan dari data sekunder rekam medis pasien. Prevalensi sifilis pada pasien terutama dari jenis kelamin dinilai sebagai perempuan atau laki-laki, sedangkan manifestasi klinis sifilis yang dilibatkan pada peneltian ini meliputi Sifilis primer (S-1), sekunder (S-II), laten, dan tersier (S-III).

Data yang diperoleh disajikan dalam bentuk angka dan persentase secara deskriptif. Seluruh data kemudian dilakukan analisis lebih jauh secara deskriptif dengan piranti lunak SPSS versi 20 untuk Windows.

\section{HASIL PENELITIAN}

Berdasarkan pengamatan pada pasien dengan sifilis di Poliklinik Kulit dan Kelamin RSUD Mangusada Badung periode Januari 2017-Desember 2018, maka didapatkan hasil seperti Tabel 1 berikut. Sebagian besar pasien dengan Infeksi Menular Seksual (IMS) tidak terdiagnosis dengan penyakit sifilis (89,46\%), sedangkan yang terdiagnosis dengan penyakit sifilis hanya sebanyak 35 pasien 
Tabel 1 Karakteristik pasien sifilis di Poliklinik kulit \& Kelamin RSD Mangusada Kabupaten Badung periode Januari 2017 Desember 2018

\begin{tabular}{lc}
\hline Variabel & $\mathbf{N}(\%)$ \\
\hline Infeksi Menular Seksual (IMS) & \\
$\quad$ Sifilis & $35(10,54)$ \\
$\quad$ Non-Sifilis & $297(89,46)$ \\
Jenis Kelamin & \\
$\quad$ Laki - laki & $13(37,15)$ \\
$\quad$ Perempuan & $22(62,85)$ \\
Manifestasi Klinis & \\
Stadium Primer & $0(0,00)$ \\
Stadium Sekunder & $3(8,58)$ \\
Stadium Lanjut & $32(91,42)$ \\
Kasus Sifilis & \\
Baru & $28(80,00)$ \\
Lama & $7(20,00)$ \\
\hline
\end{tabular}

$(10,54 \%)$ (Tabel 1). Sebagian besar pasien dengan penyakit sifilis adalah berjenis kelamin perempuan $(62,85 \%)$ diikuti dengan laki-laki $(37,15 \%)$. Berdasarkan manifestasi klinisnya, hasil penelitian ini menunjukkan bahwa sebagian besar pasien dengan sifilis berata pada stadium lanjut $(91,41 \%)$, diikuti dengan stadium sekunder $(8,58 \%)$, dan tidak ada pasien yang berada pada stadium primer $(0,00 \%)$ tercatat pada penelitian ini (Tabel 1$)$.

\section{PEMBAHASAN}

Sifilis merupakan infeksi menular (IMS) yang disebabkan oleh bakteri Treponema Pallidum. ${ }^{9}$ Bakteri Treponema Pallidum subspecies Pallidum kemudian akan menyebabkan muncul lesi pada kulit dan dapat bermanifestasi sistemik. ${ }^{9}$ Infeksi ini ditularkan melalui kontak seksual atau dari ibu kepada bayi melalui plasenta, dapat juga ditularkan melalui transfusi darah. Sifilis melewati beberapa stadium, yaitu stadium primer, stadium sekunder, stadium tersier dan sifilis yang tidak menunjukkan gejala klinis disebut sebagai sifilis laten. Stadium laten merupakan stadium sifilis tanpa gejala klinis sifilis primer ataupun sekunder namun pemeriksaan serologis menunjukkan hasil yang reaktif., 3

Pada penelitian ini, total kasus sebanyak 332 orang, didapatkan total kasus sifilis sebesar 35 kasus (10,54\%) dengan jumlah kasus baru pada penderita sifilis sebesar 28 kasus (80,00\%). Jumlah kasus sifilis ini sedikit berbeda dengan penelitian yang dilakukan oleh Kusnsan A pada tahun 2013 menyatakan bahwa angka IMS untuk prevalensi sifilis turun dari $14 \%$ menjadi $0,7 \% .{ }^{12} \mathrm{Hal}$ ini dapat dipahami karena pada penelitian oleh Kusnsan
A telah dilakukan intervensi berupa penyuluhan kepada responden untuk memahami IMS diantaranya, tidak melakukan hubungan seks secara tidak normal, menjaga penularan penyakit dengan penggunaan kondom dan segera pergi ke fasilitas kesehatan atau dokter praktek bila muncul gejala IMS. ${ }^{12}$ Intervensi pengetahuan yang intensif ini dilakukan untuk menurunkan angka IMS khususnya kasus sifilis.

Hasil penelitian ini juga menunjukkan bahwa sebagian besar pasien dengan sifilis berada pada manifestasi klinis stadium lanjut. Hasil ini tidak jauh berbeda dengan penelitian yang dilakukan oleh Saputri BYA dan Murtiastutik D tahun 2019 di RSUD Dr. Soetomo Surabaya pada periode tahun 2009-2017 yang mendapatkan kasus sifilis lanjut sebanyak 28 kasus. ${ }^{13}$ Namun, jumlah pasien ini tidak semuanya diperiksakan serologi sifilis, hanya pada beberapa kasus yang memiliki resiko tinggi seperti pasien dengan keluhan kondiloma akuminta atau ulkus di kelamin. Perbandingan diagnosa sifilis lanjut dengan seluruh jumlah pasien baru di divisi IMS menjadi kecil jika dibandingkan angka kejadian sifilis lanjut di dunia. Diagnosa sifilis lanjut dapat ditegakkan hanya melalui hasil tes serologisnya yang positif. ${ }^{14} \mathrm{Hal}$ tersebut terjadi karena pada stadium sifilis lanjut penderita tidak merasakan keluhan dan tidak ada gejala klinis yang muncul sehingga penderita tidak akan datang ke rumah sakit ataupun fasilitas kesehatan.

Hasil karakteristik sampel sifilis sekunder di RSUD Mangusada Badung ditemukan sebanyak 3 kasus atau menempati proporsi sebanyak $8,58 \%$. Sedangkan penelitian yang dilakukan oleh Saputri BYA dan Murtiastutik D mendapatkan jumlah kasus sifilis primer dan sekunder sebanyak 69 kasus. ${ }^{13}$ Perbandingan ini dimaksudkan untuk melihat seberapa besar perbandingan diagnosa sifilis lanjut jika dibandingkan dengan seluruh diagnosa yang ada di Poliklinik RSD Mangusada Badung dengan jumlah kasus di Divisi IMS RSUD Dr. Soetomo Surabaya. Hal ini terjadi karena pada sifilis primer \& sekunder menimbulkan lesi yang khas. Pada sifilis primer akan ditemukan lesi primer di area genitalia, perianal atau berupa chancre namun, pada wanita tidak chancre mudah terdiagnosis hingga berkembang menjadi sifilis sekunder. Lesi pada sifilis sekunder berupa ruam berwarna tembaga yang hilang dengan cepat hilang kemudian, muncul erupsi makulopapular yang simetris pada daerah badan dan ekstrimitas, termasuk telapak tangan dan kaki yang mudah untuk di sadari oleh penderita.

Prevalensi penderita dengan sifilis terbanyak didominasi oleh perempuan dengan jumlah 22 kasus (62,85\%). Tingginya angka prevalensi penderita perempuan pada penelitian ini berbeda 
dengan hasil penelitian yang dilakukan oleh Mutagoma M dkkyang menyebutkan bahwa penderita sifilis lebih banyak terjadi pada laki-laki Afrika sesuai penelitian WHO. ${ }^{15}$ Menurut Saputri BYA dan Murtiastutik D prevalensi berdasarkan jenis kelamin memiliki kesimpulan yang sama seperti penelitian Mutagoma M dkk dimana, penderita sifilis lebih banyak terjadi pada laki-laki sebanyak sebanyak 26 kasus $(73,1 \%)$ dibandingkan perempuan sebanyak 11 kasus $(26,9 \%) .{ }^{15} \mathrm{Hal}$ yang mungkin menyebabkan fenomena pada dominasi jenis kelamin perempuan pada penelitian ini yaitu, sejak tahun 2018 di wilayah Kabupaten Badung wajib untuk melakukan pemeriksaan tes serologis sifilis pada saat Antenatal Care (ANC) sehingga perempuan lebih banyak terjaring daripada lakilaki. Namun, hal ini memerlukan analisa lebih lanjut untuk mendapatkan gambaran yang lebih representatif kejadian sifilis.

\section{SIMPULAN}

Hasil penelitian ini menunjukkan bahwa sebagian besar pasien yang terinfeksi penyakit siflis di RSUD Mangusada Badung adalah berjenis kelamin perempuan dan memiliki manifestasi klinis stadium laten.

\section{KONFLIK KEPENTINGAN}

Tidak terdapat konflik kepentingan dalam penelitian ini.

\section{ETIKA PENELITIAN}

Penelitian deskriptif ini telah mendapat persetujuan etik dari Komisi Etik dan Bidang Pelayanan RSUD Mangusada Badung sebelum penelitian berjalan.

\section{PENDANAAN}

Penulis bertanggung jawab secara penuh terhadap pendananaan penelitian ini tanpa melibatkan pihak sponsor manapun.

\section{KONTRIBUSI PENULIS}

Seluruh penulis berkontribusi penuh terhadap penulisan laporan penelitian ini baik dari tahap pembuatan kerangka konsep penelitian, pencarian data, analisis data, hingga penyampaian hasil penelitian secara deskriptif.

\section{DAFTAR PUSTAKA}

1. Harahap M. Sexually transmitted diseases in Indonesia. Br J Vener Dis. 1980;56(5):282-284.

2. Joesoef MR, Gultom M, Irana ID, et al. High rates of sexually transmitted diseases among male transvestites in Jakarta, Indonesia. Int J STD AIDS. 2003;14(9):609-613.

3. Aral SO. Sexually transmitted diseases: magnitude, determinants and consequences. Int J STD AIDS. 2001;12(4):211-215.

4. Whiteside JL, Katz T, Anthes T, Boardman L, Peipert JF. Risks and adverse outcomes of sexually transmitted diseases. Patients' attitudes and beliefs. J Reprod Med. 2001;46(1):34-38.

5. Guaschino S. Complications of sexually transmitted diseases: clinical course and treatment. Ann Ist Super Sanita. 2000;36(4):431-435.

6. Mabey D. Epidemiology of sexually transmitted infections: worldwide. Medicine. 2014;42(6):287-290.

7. Shannon CL, Klausner JD. The growing epidemic of sexually transmitted infections in adolescents: a neglected population. Curr Opin Pediatr. 2018;30(1):137-143.

8. Majid N, Bollen L, Morineau G, et al. Syphilis among female sex workers in Indonesia: need and opportunity for intervention. Sex Transm Infect. 2010;86(5):377-383.

9. Peeling RW, Mabey D, Kamb ML, Chen XS, Radolf JD, Benzaken AS. Syphilis. Nat Rev Dis Primers. 2017;3:17073.

10. Kojima N, Klausner JD. An Update on the Global Epidemiology of Syphilis. Curr Epidemiol Rep. 2018;5(1):24-38.

11. Chan R. Sexually transmitted infections in Asia and the Pacific--an epidemiological snapshot. Sex Transm Infect. 2011;87 Suppl 2(Suppl 2):ii14-ii15.

12. Kusnsan A. Analisis Hubungan Determinan Kejadian Penyakit Infeksi Menular Seksual (IMS) Pada Wanita Penjaja seksual (WPS). Jurnal Kesehatan. 2013;4(2): 344-350.

13. Saputri BYA, Murtiastutik D. Studi Retrospektif: Sifilis Laten. Berkala Ilmu Kesehatan Kulit dan Kelamin. 2019;31(1):46-64.

14. Puspawati NMD, Wiraguna AAGP, Indira IGAAE, Sari IADP. Late latent syphilis accompanied by ocular syphilis in a geriatric patient: a case report. Bali Medical Journal. 2020;9(1):208-210.

15. Mutagoma M, Nyirazinyoye L, Sebuhoro D, Riedel DJ, Ntaganira J. Syphilis and HIV prevalence and associated factors to their co-infection, hepatitis $\mathrm{B}$ and hepatitis $\mathrm{C}$ viruses prevalence among female sex workers in Rwanda. BMC Infect Dis. 2017;17(1):525.

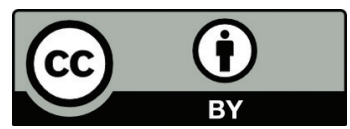

This work is licensed under a Creative Commons Attribution 